\title{
Effects of Water and Salt Movement On Photosynthetic Production Characteristics and Yield Formation of Cotton On Coastal Saline Land
}

\author{
Guoyi Feng \\ Hebei Academy of Agriculture and Forestry Sciences \\ Qian Zhang \\ Hebei Academy of Agriculture and Forestry Sciences \\ Chitao Sun \\ Shandong Agricultural University \\ Xiaopeng Lei \\ Hebei Academy of Agriculture and Forestry Sciences

\section{Shulin Wang} \\ Hebei Academy of Agriculture and Forestry Sciences

\section{Yan Wang} \\ Hebei Academy of Agriculture and Forestry Sciences

\section{Ming Dong \\ Hebei Academy of Agriculture and Forestry Sciences \\ Qinglong Liang \\ Hebei Academy of Agriculture and Forestry Sciences \\ Yongzeng Lin \\ Hebei Academy of Agriculture and Forestry Sciences \\ Hong Qi ( $\sim$ qihong83@126.com ) \\ Hebei Academy of Agriculture and Forestry Sciences}

\section{Research}

Keywords: coastal saline land, cotton, water and salt movement, photosynthetic production, yield formation

Posted Date: October 12th, 2021

DOI: https://doi.org/10.21203/rs.3.rs-944729/v1

License: (c) (1) This work is licensed under a Creative Commons Attribution 4.0 International License. Read Full License 


\section{Abstract \\ Background}

In order to study the effects of spatial distribution and yearly migration variations of soil water and salt in coastal saline land on photosynthetic production and yield formation of cotton, spatial distribution characteristics of water content, salinity, and pH in soil at 0-200 cm depths in 3 cotton fields that were similar in locality but differed markedly in degree of salinization were determined in April through October, and photosynthetic characteristics and photosynthate accumulation of cotton were also determined.

\section{Results}

The study shows that, the slightly salinized cotton field had lower soil salinity and $\mathrm{pH}$, where soil water content was lower in rainy season (July-August), and at the late reproductive stage (September-October), soil water content was markedly higher than that in the moderately salinized cotton field, where cotton suffered smaller salt-alkali stress, photosynthetic production matched well with hydrothermal resource, the sink organ had a long photosynthate accumulation time and was at the active material accumulation stage for a long time; salt-alkali stress to the moderately salinized cotton field was relieved in rainy season, but at the early reproductive stage (April-June) and the late reproductive stage of cotton, salt-alkali stress remained evident, and photosynthetic production fit more poorly with the rich photothermal resource stage; the severely salinized cotton field subjected to prolonged high salt-alkali stress resulted in low levels of photosynthetic production capacity and yield.

\section{Conclusions}

For the severely salinized cotton field, salt inhibition and other relevant agronomic actions should be taken with greater efforts; for the moderately salinized cotton field, water and fertilizer management should be tightened at the early reproductive stage of cotton; for the slightly salinized cotton field, high-quality efficient cotton production should be developed.

\section{Introduction}

Soil salinization has caused serious impact on global agricultural productivity and sustainable development, and to date, there is about $9.5 \times 108 \mathrm{hm} 2$ of salinized land worldwide, and over time, the area of the salinized land continues to increase and the level of salinization is continuously exacerbated (Qadir et al. 2008; Setia et al. 2012). China has a considerably large area of coastal saline land accounting for $40 \%$ of the total area of the saline land nationwide (Yang 2008; Dong 2010), the coastal areas have generally annual precipitations above $500 \mathrm{~mm}$, indicating huge potential for agricultural production exploitation and utilization. Soil salinization of the coastal saline land affects soil physiochemical properties and plant growth (Zhang et al. 2010); rational exploitation and utilization of coastal saline land resource is one of important ways to address farmland resource plummeting and guarantee grain production security in China.

Numerous researchers have conducted in-depth studies on factors of spatial distribution of soil salinity in coastal saline land, effects of saline land amelioration actions on soil physiochemical properties, and mechanism of action of plant photosynthetic production (Fall 2017; Shan et al. 2011; Zhang et al. 2012;Wang et al. 2015; Wang et al. 2017), revealing a phenomenon during production practice that amelioration performance varied much after the same amelioration action was taken in the same area with the same groundwater salinity. In previous studies, variations in spatial distribution of soil water and salt in coastal saline land are mostly used to evaluate amelioration action performance, and more studies on soil water and salt movement focus on one period or part of the soil layer, resulting in discrepancy between soil amelioration 
performance evaluated based on the data during one period and crop production. Crop growth and development on the salinized land was seriously affected by soil salinity and pH level [4]; salinity altered crop photosynthetic system or structure-related physiological and biochemical processes, leading to decline in net photosynthetic rate (Kao et al. 2006). Fewer of the studies to date focus on the impact of variation in spatial distribution of soil water and salts during crop reproduction on crop photosynthetic production, while highly salt-resistant cotton is generally accepted as a pioneer crop for saline land exploitation (Dong 2010) and one important cash crop in China where its planting area accounts for about $15 \%$ of the cotton planting area in the world and its yield accounts for about 25\% of the cotton yield worldwide (Yu 2013); planting cotton in coastal saline land has important social and economic benefits. In this study, cotton fields in native state that differ much in degree of salinization within one coastal region were selected, variability of spatial water-salt distribution in soil layers of the salinized cotton fields at 0-200 cm depths was investigated in 3 time intervals, April-June, July-August, and September-October, depending on cotton production, climate, and precipitation in the coastal region, photosynthetic production characteristics of cotton varying with spatial distribution characteristics of soil water and salts were summarized, and their effects on photosynthetic production and yield of cotton were analyzed, so as to provide certain theoretical rationale for amelioration action establishment and adjudication objectivity and comprehensiveness.

\section{Materials And Methods}

The experiment was performed in Hebei state-owned Haixing Farm $\left(38^{\circ} 21^{\prime} \mathrm{N}, 117^{\circ} 31^{\prime} \mathrm{E}\right)$ in $2015-2016$. Three cotton fields (each having an area greater than $3.0 \mathrm{hm}^{2}$ ) differing much in topography, elevation, and bulk density of soil were selected, the soil of each cotton field was coastal saline soil, and according to previous coastal saline land classification method (Dong et al.2009), these 3 cotton fields were classified into 3 categories varying in degree of salinization based on salt content of the plow layer (0-20 cm deep) in the second half of April; soil salinity and nutrient composition of the soil plow layer in each cotton field are shown in Table 1.

Table 1

Terrain,hydrology and soil nutrient status of the cotton fields different in saline-alkali level

\begin{tabular}{|c|c|c|c|c|c|c|c|}
\hline $\begin{array}{l}\text { Code } \\
\text { name }\end{array}$ & $\begin{array}{l}\text { Salt content } \\
\text { of } \\
\text { plow-layer } \\
/\left(\mathrm{g} \cdot \mathrm{kg}^{-1}\right)\end{array}$ & $\begin{array}{l}\text { Saline- } \\
\text { alkali } \\
\text { level }\end{array}$ & $\begin{array}{l}\text { Organic } \\
\text { matter } /\left(\mathrm{g} \cdot \mathrm{kg}^{-1}\right)\end{array}$ & $\begin{array}{l}\text { Total N } \\
/\left(\mathrm{g} \cdot \mathrm{kg}^{-1}\right)\end{array}$ & $\begin{array}{l}\text { Alkali } \\
\text { hydrolysable } \\
\text { nitrogen } \\
/\left(\mathrm{mg} \cdot \mathrm{kg}^{-1}\right)\end{array}$ & $\begin{array}{l}\text { Available P } \\
/\left(\mathrm{mg} \cdot \mathrm{kg}^{-1}\right)\end{array}$ & $\begin{array}{l}\text { Available K } \\
/\left(\mathrm{mg} \cdot \mathrm{kg}^{-1}\right)\end{array}$ \\
\hline$A$ & $5.0 \sim 10.0$ & Severe & $7.67 \pm 0.31 \mathrm{c}$ & $0.44 \pm 0.02 c$ & $20.06 \pm 1.00 \mathrm{c}$ & $3.88 \pm 0.15 c$ & $215.54 \pm 9.27 a$ \\
\hline B & $3.0 \sim 5.0$ & Moderate & $8.88 \pm 0.44 b$ & $0.71 \pm 0.03 b$ & $25.71 \pm 1.26 b$ & $9.62 \pm 0.38 b$ & $198.63 \pm 9.31 b$ \\
\hline C & $1.0 \sim 3.0$ & Mild & $10.27 \pm 0.50 a$ & $0.82 \pm 0.03 a$ & $35.43 \pm 1.47 a$ & $11.71 \pm 0.48 a$ & $173.88 \pm 6.69 c$ \\
\hline
\end{tabular}

Note:Different letters in the same column mean significant difference at the 0.05 probability level

All the previous crop stubbles were cotton following single cropping system. Cotton cultivar Jimian 228 was sowed in a rush while the soil was moist on Apr. 21, 2015 and Apr. 23, 2016, row spacing configuration was (90+45) cm, topsoil up to 5 $\mathrm{cm}$ depth was pushed between mulches at the time of sowing in narrow furrows of about $10 \mathrm{~cm}$ depth plowed by the furrower, and dressing furrows (ca. $15 \mathrm{~cm}$ deep) were dug in the middle of wide rows for basal dressing; at the time of sowing, urea $\left(450 \mathrm{~kg} \cdot \mathrm{hm}^{-2}\right)$ and calcium superphosphate $\left(750 \mathrm{~kg} \cdot \mathrm{hm}^{-2}\right)$ were applied. Cultivation was performed by wide plastic film mulching, 2 rows per mulch, and dibbling was followed by mulching. On Jul. 20, topping was completed, topdressing fertilizer (urea: $150 \mathrm{~kg} \cdot \mathrm{hm}^{-2}$ ) was applied once in rainy season, while field management actions such as simplified pruning, chemical regulation, and disease and pest control were the same as conventional ones in local agricultural production. 
Throughout cotton reproduction stage (April through October), the soil of each cotton field at $0-200 \mathrm{~cm}$ depths was aliquotted into 10 soil layers, the soil in each soil layer was monthly sampled for determination of water content and salinity, and soil sampling each time was done in one day in order to minimize the impact of variability of soil water-salt distribution with time on sampling. Each sample was weighed, dried to constant weight at $105^{\circ} \mathrm{C}(6-8 \mathrm{~h})$, cooled down in a desiccator for $30 \mathrm{~min}$, and then weighed again to determine water content of the soil sample by mass; next, the dried soil and water were mixed at a ratio of 1:5 to result in extraction solution; then, $\mathrm{pH}$ was determined by $\mathrm{PHS}-3 \mathrm{pH}$ meter, electrical conductivity was determined by DDS2307 conductivity meter, and soil salt content was obtained using conversion formula $y=2.8311 x+0.2932$, where $y$ is the salt content $\left(\mathrm{g} \mathrm{kg}^{-1}\right)$ and $\mathrm{x}$ is the electrical conductivity $(\mathrm{ms} \cdot \mathrm{cm}-1)$. Six points per cotton field were selected for the assays.

At basal and critical development stages of cotton yield formation, the following photosynthetic indicators were determined:

1) Leaf area index: determined by LAI-2200 canopy analyzer (LI-Cor, USA) in early morning or at dusk without direct sunlight. Firstly, the operator placed the probe level above the canopy, pressed down the test button, and after the instrument buzzed twice, placed the probe into crop population, kept it level, pressed the test button, and after listening to two buzz sounds, moved the probe horizontally at a uniform rate, and measured leaf areas at different positions in horizontal direction inside the canopy.

2) Canopy apparent photosynthesis rate and canopy respiration rate: directly determined by $\mathrm{GXH}-305$ infra-red $\mathrm{CO}_{2}$ analyzer in the field. The height of the assimilation chamber was set depending on plant height at each reproductive stage, the chamber was a closed-circuit system, inside which a fan was installed to agitate the gas while the frame was shrouded with transparent polyester film. Canopy apparent photosynthesis rate was determined in sunny days while light intensity was stabilized at $1200-1400 \mu \mathrm{mol} \cdot \mathrm{m}^{-2} \cdot \mathrm{s}^{-1}$ (at 9:00-11:00 Beijing time). Duration of each assay was $60 \mathrm{~s}$. While the light was masked by special lampshade, canopy respiration rate was determined by the same method as that for determination of canopy apparent photosynthesis rate. For cotton plants treated in different ways, recurrent measurement was conducted. Meanwhile, soil respiration rate of a plot with similar structure of cotton population was measured to correct the measured values of population photosynthesis rate and population respiration rate.

3) SPAD value of relative chlorophyll content: Leaf SPAD value was determined by SPAD-502 chlorophyll meter (Minolta, Japan). Top fourth leaf of the cotton's main stem prior to topping and top second leaf of the cotton's main stem after topping were selected for measurement, and 10 leaves were selected and delineated at each of 3 selected points per cotton field.

4) Dry mass accumulation and allocation: In each cotton field, 6 cotton plants representative in growth and development were selected, degraded, and fixed at $105^{\circ} \mathrm{C}$ for $30 \mathrm{~min}$, completely dried at $80^{\circ} \mathrm{C}$, and then weighed; logistic equation $\mathrm{y}=\mathrm{a} /(1+\mathrm{be}-\mathrm{cx})$ was used to simulate cotton plant photosynthate accumulation process.

5) Yield: Prior to harvesting, 6 sampling points, $30 \mathrm{~m} 2$ each, in each cotton field were randomly selected, total number of plants and total number of bolls at each sampling point were investigated and converted into number of bolls per plant and number of bolls per unit area, and the yield was calculated based on actually harvested seed cotton; 2 neighboring narrow rows per point were randomly selected, each plant per row was investigated, a total of 10 plants were harvested, air dried to determine average boll weight, and ginned to determine lint percentage, then lint yield was calculated based on the average boll weight and the lint percentage.

Experimental data were statistically analyzed by SPSS11.0 and plotted by SigmaPlot 10.0.

\section{Results}




\subsection{Characteristics of soil water and salt movement in cotton fields varying in degree of salinization}

\subsubsection{Spatiotemporal variation characteristics of soil water content}

Water content determination of soil layers at 0-200 cm depths in different types of cotton fields (Figure 1) shows that, soil water content increased gradually in ascending order of depth, the lowest water content was noted in April through June, while the highest water content was noted in July through August. Among variably salinized cotton fields, the severely salinized cotton field had the highest soil water content. In April through June, soil water contents of soil layers at $0-80 \mathrm{~cm}$ depths in the slightly salinized cotton field were $12.6 \%-19.8 \%$, not evidently differing from those in the moderately salinized cotton field and $11.4 \%-30.5 \%$ lower than those in the severely salinized land; in July through August, soil water contents of soil layers at $0-140 \mathrm{~cm}$ depths were $14.1 \%-24.5 \%$, which were $4.6 \%-15.5 \%$ lower than those in the moderately salinized cotton field and $9.6 \%-33.7 \%$ lower than those in the severely salinized cotton field; in September through October, soil water contents of soil layers at $0-140 \mathrm{~cm}$ depths were $13.9 \%-24.4 \%$, which were $4.7 \%-12.8 \%$ higher than those in the moderately salinized cotton field and $4.2 \%-29.8 \%$ lower than those in the severely salinized cotton field.

\subsubsection{Spatiotemporal variation characteristics of salinity}

Soil salinity is an important indicator characterizing degree of salinization. Salt content determination of soil layers at 0$200 \mathrm{~cm}$ depths in different types of cotton fields (Figure 2) shows that, soil salt content increased gradually in ascending order of depth. In terms of variability between months, the highest salinity was noted in April through June while the lowest salinity was noted in July through August. In terms of variability between cotton fields varying in degree of salinization, the highest salt content was observed in the severely salinized cotton field, and the salt contents of each soil layer was not lower than $5.0 \mathrm{~g} \cdot \mathrm{kg}^{-1}$; in the slightly salinized cotton field, salt contents of soil layers at $0-140 \mathrm{~cm}$ depths were not higher than $3.0 \mathrm{~g} \cdot \mathrm{kg}^{-1}$; in the moderately salinized cotton field, salt contents of soil layers at $0-100 \mathrm{~cm}$ depths were $3.0-5.0 \mathrm{~g} \cdot \mathrm{kg}^{-1}$ in April through June, not higher than $3.0 \mathrm{~g} \cdot \mathrm{kg}^{-1}$ in July through August, and not more than $4.0 \mathrm{~g} \cdot \mathrm{kg}^{-1}$ in September through October; in the slightly and moderately salinized cotton fields, smaller differences in salt contents of soil layers at 0-140 $\mathrm{cm}$ depths in July through August were observed. Salt contents of soil layers at $0-140 \mathrm{~cm}$ depths in the slightly salinized cotton field in April through June were 39.2\%-65.1\% lower than those in the severely salinized cotton field, and $0.6 \%$ 42.9\% lower than those in the moderately salinized cotton field; in July through August, the salt contents were $40.0 \%-$ $77.0 \%$ lower than those in the severely salinized cotton field and $3.5 \%-43.1 \%$ lower than those in the moderately salinized cotton field; in September through October, the salt contents were 37.6\%-73.4\% lower than those in the severely salinized cotton field and $3.0 \%-51.2 \%$ lower than those in the moderately salinized cotton field.

\subsubsection{Spatiotemporal variation characteristics of $\mathrm{pH}$}

Determination of $\mathrm{pH}$ for soil layers at 0-200 cm depths in different types of cotton fields (Figure 3) shows that, the severely salinized cotton field had higher $\mathrm{pH}$ values than other types of cotton fields; $\mathrm{pH}$ values of soil layers at $0-140 \mathrm{~cm}$ depths in the slightly salinized cotton field were lower than those in the moderately salinized cotton field, whereas $\mathrm{pH}$ values of other soil layers in various types of cotton fields did not differ significantly. In terms of variability of $\mathrm{pH}$ between months, the highest $\mathrm{pH}$ occurred in April through June while the lowest $\mathrm{pH}$ was observed in July through August. All the $\mathrm{pH}$ values of various soil layers in the severely salinized cotton field during the assay were greater than 8.0. In April through June, $\mathrm{pH}$ values of soil layers at $0-140 \mathrm{~cm}$ depths in the slightly salinized cotton field were $7.4-8.0,5.8 \%-11.1 \%$ lower than those in the severely salinized cotton field and 3.5\%-7.6\% lower than those in the moderately salinized cotton field; in July through August, $\mathrm{pH}$ values remained at $7.0-7.5,12.2 \%-17.2 \%$ lower than those in the severely salinized cotton field and $1.4 \%-3.7 \%$ lower than those in the moderately salinized cotton field; in September through October, pH values in the slightly salinized cotton field remained at $7.5-7.8,5.0 \%-9.9 \%$ lower than those in the severely salinized cotton field and $5.0 \%-7.2 \%$ lower than those in the moderately salinized cotton field.

\subsection{Photosynthetic characteristics of the cotton in cotton fields varying in degree of salinization}




\subsubsection{Leaf area index and chlorophyll content}

The study shows that (Figure 4), for each type of cotton field, both leaf area index and chlorophyll content of the cotton canopy increased until peaking in the second half of August, and then started to decrease; the differences among cotton fields varying in degree of salinization were evident. In the severely salinized cotton field, values and ranges of variation of both indicators were smaller, remaining within narrower ranges throughout the reproductive stage; the values of both indicators in the moderately salinized cotton field in June and July were obviously lower than those in the slightly salinized cotton field, and when they peaked in the second half of August, their differences from those in the slightly salinized cotton field became smaller, then they decreased quickly; the values of both indicators in the slightly salinized cotton field were higher, and decreased more slowly at the late stage. In the slightly salinized cotton field, values of leaf area index were $0.33-4.38,105.3 \%-290.0 \%$ higher than those in the severely salinized cotton field and $0.1 \%-73.2 \%$ higher than those in the moderately salinized cotton field; chlorophyll SPAD values were $34.8-49.6,23.5 \%-54.3 \%$ higher than those in the severely salinized cotton field and $0.4 \%-38.0 \%$ higher than those in the moderately salinized cotton field.

\subsubsection{Canopy apparent photosynthesis rate and canopy respiration rate}

The study shows that (Figure 3), canopy apparent photosynthesis rate and canopy respiration rate of cotton in each type of cotton field increased until peaking in the second half of August, and then started to decrease; the differences in both indicators of the cotton between cotton fields varying in degree of salinization were significant. In the severely salinized cotton field, values and ranges of variation of both indicators were smaller; the values of both indicators in the moderately salinized cotton field in June and July were markedly less than those in the slightly salinized cotton field, and when they peaked in the second half of August, their differences from those in the slightly salinized cotton field became smaller, and then the values decreases quickly; the values in the slightly salinized cotton field were higher, and decreased more slowly at the late stage. In the slightly salinized cotton field, canopy apparent photosynthesis rates were $21.8-38.6 \mu \mathrm{mol} /\left(\mathrm{m}^{2} \mathrm{~s}\right)$, $30.9 \%-339.5 \%$ higher than those in the severely salinized cotton field and $7.4 \%-183.6 \%$ higher than those in the moderately salinized cotton field; the canopy respiration rates were $3.65-9.51 \mu \mathrm{mol} /\left(\mathrm{m}^{2} \mathrm{~s}\right), 46.0 \%-162.8 \%$ higher than those in the severely salinized cotton field, 3.6\%-22.2\% higher than those in the moderately salinized cotton field at the early reproductive stage, and $16.2 \%-25.3 \%$ lower than those in the moderately salinized cotton field at other reproductive stages.

\subsection{Photosynthate accumulation and allocation characteristics of organs}

Photosynthate accumulation and allocation determination for source and sink organs of cotton plants in different types of cotton fields (Table 2) shows that, for photosynthate accumulation of source and sink organs in the severely salinized cotton field, linear growth stage started and ended earlier, duration and active mass accumulation stage were shorter, and the maximum growth rate was smaller; source organs in the moderately and slightly salinized cotton fields differed not much in linear growth stage ending time and maximum growth rate onset time, but varied much in linear growth stage starting time; photosynthate accumulation of the sink organ increased with higher degree of salinization, linear growth stage ending time and maximum growth rate onset time were expedited, while the growth stage, maximum growth rate, and active mass accumulation stage decreased. In terms of photosynthate accumulation of the source organ, linear growth stage starting time, linear growth stage ending time, and maximum growth rate onset time in the slightly salinized cotton

field were $2-5 d, 28-30 d$, and 16-17 d later than those in the severely salinized cotton field, respectively, and $-4 d,(-1)-3 d$, and (-1) $-(-3)$ d earlier than those in the moderately salinized cotton field, respectively; the linear growth stage, maximum growth rate, and active mass accumulation stage of photosynthate accumulation in the slightly salinized cotton field were $89.2 \%-98.7 \%, 57.1 \%-71.3 \%$, and $89.2 \%-149.3 \%$ higher than those in the severely salinized cotton field, respectively, and $6.0 \%-16.9 \%, 8.0 \%-18.1 \%$, and $5.9 \%-17.0 \%$ higher than those in the moderately salinized cotton field, respectively. In terms of photosynthate accumulation of the sink organ, linear growth stage starting time, linear growth stage ending time, and maximum growth rate onset time in the slightly salinized cotton field were 24-27 d, 38-50 d, and 31-39 d later than those 
in the severely salinized cotton field, respectively, and 14-18 d, 25-35 d, and 20-26 d earlier than those in the moderately salinized cotton field, respectively; the linear growth stage, maximum growth rate, and active mass accumulation stage of photosynthate accumulation were $44.3 \%-69.6 \%, 163.4 \%-182.1 \%$, and $44.3 \%-69.6 \%$ higher than those in the severely salinized cotton field, respectively, and $28.7 \%-43.0 \%, 49.7 \%-50.6 \%$, and $28.7 \%-43.0 \%$ higher than those in the moderately salinized cotton field, respectively.

Table 2 Characteristics of the photosynthesizing substance accumulation of source and sink in the cotton relative to soil saline-alkali level

\begin{tabular}{|c|c|c|c|c|c|c|c|c|c|c|}
\hline $\begin{array}{l}\text { Type of } \\
\text { the cottor } \\
\text { field }\end{array}$ & & Fitting equation & $\mathrm{R}$ & $\begin{array}{l}\text { TPA } \\
(\mathrm{kg} \cdot \\
\mathrm{hm}-2)\end{array}$ & $\begin{array}{l}\text { T1 } \\
\text { (d) }\end{array}$ & $\begin{array}{l}\mathrm{T} 2 \\
\text { (d) }\end{array}$ & $\begin{array}{l}\text { T3 } \\
\text { (d) }\end{array}$ & $\begin{array}{l}\text { Vmax } \\
(\mathrm{kg} \cdot \\
\left.\mathrm{hm}^{-2} \cdot \mathrm{d}^{-1}\right)\end{array}$ & $\begin{array}{l}\text { T0 } \\
\text { (d) }\end{array}$ & $\begin{array}{l}P \\
\text { (d) }\end{array}$ \\
\hline \multicolumn{11}{|l|}{2015} \\
\hline \multirow{3}{*}{$\begin{array}{l}\text { Source } \\
\text { organ }\end{array}$} & A & $\begin{array}{l}y=1625.7 /(1+4971.2 e- \\
0.1424 x)\end{array}$ & $0.9996 * *$ & $1645.0 \mathrm{c}$ & $51 c$ & $69 b$ & $18 c$ & $48 c$ & $60 b$ & $42 c$ \\
\hline & B & $\begin{array}{l}y=3833.0 /(1+115.0 e- \\
0.0606 x)\end{array}$ & $0.9938^{* *}$ & $3899.5 b$ & $58 a$ & $100 a$ & $42 b$ & $58 b$ & $78 a$ & $99 b$ \\
\hline & C & $\begin{array}{l}y=4799.3 /(1+75.6 e- \\
0.0571 x)\end{array}$ & $0.9997 * \star$ & $4822.8 a$ & $53 b$ & $99 a$ & $46 a$ & $69 a$ & $76 a$ & $105 a$ \\
\hline \multirow{3}{*}{$\begin{array}{l}\text { Sink } \\
\text { organ }\end{array}$} & $A$ & $\begin{array}{l}y=674.8 /(1+203.2 e- \\
0.0789 x)\end{array}$ & $0.9905^{\star \star}$ & $710.6 c$ & $51 c$ & $84 c$ & $33 c$ & $13 c$ & $67 c$ & $76 c$ \\
\hline & B & $\begin{array}{l}y=1417.0 /(1+252.9 e- \\
0.0703 x)\end{array}$ & $0.9987^{* *}$ & $1439.8 b$ & $60 \mathrm{~b}$ & $97 b$ & $37 b$ & $25 b$ & $79 b$ & $85 b$ \\
\hline & C & $\begin{array}{l}y=2746.5 /(1+216.1 e- \\
0.0546 x)\end{array}$ & $0.9980 * *$ & $2762.4 a$ & $74 a$ & $122 a$ & $48 a$ & $38 a$ & $98 a$ & $110 a$ \\
\hline \multicolumn{11}{|l|}{2016} \\
\hline \multirow{3}{*}{$\begin{array}{l}\text { Source } \\
\text { organ }\end{array}$} & A & $\begin{array}{l}y=1658.4 /(1+368.2 e- \\
0.1005 x)\end{array}$ & $0.9996 * *$ & $1675.9 \mathrm{c}$ & $46 c$ & $72 b$ & $26 c$ & $42 c$ & $59 b$ & $60 c$ \\
\hline & B & $\begin{array}{l}y=3904.7 /(1+113.6 e- \\
0.0621 x)\end{array}$ & $0.9953^{\star *}$ & $3968.9 b$ & $55 a$ & $97 a$ & $42 b$ & $61 b$ & $76 a$ & $97 b$ \\
\hline & C & $\begin{array}{l}y=4929.9 /(1+55.5 e- \\
0.0531 x)\end{array}$ & $0.9989 * *$ & 4971.7a & $51 b$ & $100 a$ & $50 a$ & $65 a$ & $76 a$ & $113 a$ \\
\hline \multirow{3}{*}{$\begin{array}{l}\text { Sink } \\
\text { organ }\end{array}$} & $A$ & $\begin{array}{l}y=687.4 /(1+160.4 e- \\
0.0789 x)\end{array}$ & $0.9905^{\star *}$ & $723.9 c$ & $48 c$ & $81 c$ & $33 c$ & $14 \mathrm{c}$ & $64 c$ & $76 c$ \\
\hline & B & $\begin{array}{l}y=1434.7 /(1+166.0 e- \\
0.0665 x)\end{array}$ & $0.9961^{\star \star}$ & $1465.5 b$ & $57 b$ & $97 b$ & $40 \mathrm{~b}$ & $24 b$ & $77 b$ & $90 \mathrm{~b}$ \\
\hline & C & $\begin{array}{l}y=3071.1 /(1+120.2 e- \\
0.0465 x)\end{array}$ & $0.9927^{* *}$ & $3092.8 a$ & $75 a$ & $131 a$ & $57 a$ & $36 a$ & $103 a$ & $129 a$ \\
\hline
\end{tabular}

Note:A: Cotton field with heavy saline-alkali degree; B: Cotton field with middle saline-alkali degree; C: Cotton field with mild saline-alkali degree.The implications followed by different letters are significantly different at the 0.05 probability level at same classification in same year within a column. ${ }^{\star *}$ means significant difference at $P<0.01$. T1 and T2 stands for beginning and ending date, respectively, of the photosynthesizing substance accumulation line, T3 for number of the days the process lasted, T0 for the date the highest growth rate appeared, and P for the active photosynthesizing substance accumulation period (up to $90 \%$ of the total accumulation) 


\subsection{Yields of cotton and yield components}

Based on statistics of yield measurements and actual yields (Table 3), different types of cotton fields differed significantly in yield. In the slightly salinized cotton field, seed cotton yield was more than $3000 \mathrm{~kg} \cdot \mathrm{hm}^{-2}$, average lint yield reached 1200 $\mathrm{kg} \cdot \mathrm{hm}^{-2}$, and the lint yields were $91.0 \%-130.8 \%$ higher than those in the severely salinized cotton field and $36.0 \%-40.7 \%$ higher than those in the moderately salinized cotton field. The lint yields in the moderately salinized cotton field were above $900 \mathrm{~kg} \cdot \mathrm{hm}^{-2}, 40.4 \%-64.0 \%$ higher than those in the severely salinized cotton field. It's found in further analysis of yield components that, the cotton fields varying in degree of salinization differed significantly in number of harvested plants and number of bolls per unit area, the lower the degree of salinization, the more the number of harvested plants and number of bolls per unit area; differences in boll weight and lint percentage between the severely and the moderately salinized cotton fields were insignificant, and both indicators were significantly lower than those in the slightly salinized cotton field. No evident difference was noted in cotton yield and yield components in two severely salinized cotton fields. Therefore, number of bolls per unit area was the main contributor to lower cotton yield in the severely salinized cotton field, and boll weight and lint percentage limited further increase in the yield of cotton in the moderately salinized cotton field.

Table 3 Yield and yield components of the cotton relative to type of the cotton field

\begin{tabular}{|c|c|c|c|c|c|c|c|}
\hline Year & $\begin{array}{l}\text { Code } \\
\text { name }\end{array}$ & $\begin{array}{l}\text { Plant No. } \\
/ \\
\varangle \times 10^{4} \text { plants } \cdot \mathrm{hm}^{-2} \square\end{array}$ & $\begin{array}{l}\text { Boll density } \\
/\left(\times 10^{4} \cdot \mathrm{hm}^{-2}\right)\end{array}$ & $\begin{array}{l}\text { Boll } \\
\text { weight/g }\end{array}$ & $\begin{array}{l}\text { Lint } \\
\text { percentage/\% }\end{array}$ & $\begin{array}{l}\text { Seed cotton } \\
\text { yield } \\
/\left(\mathrm{kg} \cdot \mathrm{hm}^{-2}\right)\end{array}$ & $\begin{array}{l}\text { Lint cotton } \\
\text { yield } \\
/\left(\mathrm{kg} \cdot \mathrm{hm}^{-2}\right)\end{array}$ \\
\hline \multirow[t]{3}{*}{2015} & A & $3.80 \pm 0.17 c$ & $32.5 \pm 1.53 \mathrm{c}$ & $5.58 \pm 0.20 b$ & $38.0 \pm 1.86 \mathrm{~b}$ & $1733 \pm 48.9 c$ & $658.5 \pm 21.3 c$ \\
\hline & B & $4.57 \pm 0.18 b$ & $47.5 \pm 2.14 b$ & $5.51 \pm 0.23 b$ & $38.2 \pm 1.84 b$ & $2456 \pm 74.6 b$ & $938.2 \pm 31.9 b$ \\
\hline & C & $5.09 \pm 0.22 a$ & $52.7 \pm 2.48 a$ & $6.35 \pm 0.28 a$ & $38.7 \pm 1.91 \mathrm{a}$ & $3298 \pm 115.4 a$ & $1276.3 \pm 42.8 a$ \\
\hline \multirow[t]{3}{*}{2016} & A & $3.48 \pm 0.16 \mathrm{c}$ & $28.8 \pm 1.42 \mathrm{c}$ & $5.36 \pm 0.24 b$ & $37.8 \pm 1.68 \mathrm{~b}$ & $1499 \pm 49.8 \mathrm{c}$ & $566.6 \pm 24.7 \mathrm{c}$ \\
\hline & B & $4.29 \pm 0.18 b$ & $44.7 \pm 2.15 b$ & $5.39 \pm 0.21 b$ & $37.9 \pm 1.74 b$ & $2388 \pm 66.6 b$ & $905.1 \pm 22.7 b$ \\
\hline & $\mathrm{C}$ & $5.04 \pm 0.20 a$ & $52.8 \pm 2.49 a$ & $6.37 \pm 0.26 a$ & $38.5 \pm 1.79 a$ & $3308 \pm 103.6 a$ & $1273.5 \pm 40.7 a$ \\
\hline
\end{tabular}

Note:Different letters in the same column mean significant difference at the 0.05 probability level in the same year

\section{Discussion}

\subsection{Effect of water and salt movement in coastal saline land on photosynthetic characteristics of cotton}

Photosynthesis is most sensitive to abiotic stresses, among which salt-alkali stress is an important external factor of photosynthesis (Farquhar et al. 2011). Salinity-induced variations in physiological and biochemical processes in relation to crop photosynthetic system and structures lead to reduced net photosynthetic rate (Kao et al. 2006). The combined saltalkali stress is not simply summation of salt and alkali stresses but has certain synergistic effect, thereby plants are subjected to salt stress-induced permeation injury and ion toxicity as well as alkali stress-induced high pH (Paz et al. 2014). Ion toxicity and high pH arising from salt-alkali stress will cause damage to photosystem II (PSII) reaction center of the plant so that photosynthetic electron transfer and PSII photosynthesis activity will be suppressed (Kalaji et al. 2016); under combined salt-alkali stress, photosynthetic parameters such as photosynthetic rate and chlorophyll content decreased significantly with increasing stress intensity (Yang et al. 2011); salt-alkali stress will cause significant reduction in leaf chlorophyll content of a plant (Kalaji et al. 2017; Zushi and Matsuzoe 2017). Photosynthesis-induced dry mass mainly accumulates in leaves, and under salt-alkali stress, leaf primordium genesis is suppressed and photosynthetic area per plant decreases, leading indirectly to reduced plant carbon assimilation and thus plant growth is affected (Grieve et al. 1992). This study shows that, regardless of type of salinized cotton field, soil salinity and pH peaked in April through June 
(arid and rainless spring and summer), decreased significantly in July through August (rainy summer and autumn), and increased somewhat in September through October (post-rainy autumn). In July through August, soil salt washing of the slightly salinized cotton field caused further decline in soil salinity and $\mathrm{pH}$. In the moderately salinized cotton field, soil salinity and $\mathrm{pH}$ decreased markedly due to precipitation washing, too. In September through October, $\mathrm{pH}$ values of the soil at 0-140 cm depths in the slightly salinized cotton field increased insignificantly, whereas soil salinity and $\mathrm{pH}$ in the moderately salinized cotton field increased markedly. Soil salinity and pH in the severely salinized cotton field were significantly higher than those in other types of cotton fields. Meanwhile, low salinity and low pH are conducive to increase in leaf chlorophyll content of cotton in the slightly salinized cotton field, laying a foundation for improvement in photosynthetic production and yield of cotton at the late reproductive stage (Sun and Hong 2011); in the cases of moderately and severely salinized cotton fields, even with higher soil water contents, salt-alkali stresses such as high salinity and high $\mathrm{pH}$ not only result in more intense ion injury to cotton growth but will lead to physiological drought, therefore, not only leaf growth is suppressed but leaf chlorophyll synthesis is also hindered (Yang et al. 2011). In July through August (rainy season), in slightly and moderately salinized cotton fields, salt-alkali stress is significantly relieved, leaves grow quickly, and chlorophyll content also increases significantly, resulting in significant increase in photosynthetic rate (Dong et al. 2012), indicating stronger photosynthetic production capacity. However, when early growth of cotton in the moderately salinized cotton field was evidently suppressed, soil water content was relatively high and vegetative growth became particularly pronounced; in September through October (post-rainy autumn), salinity and pH increased quickly, leaves turned yellow quickly and fell, resulting in evident decline in photosynthetic rate. In the case of severely salinized cotton field, salt-alkali stress remained at a higher level throughout the reproductive stage, resulting in significantly insufficient photosynthetic capacity.

Water content transport in coastal saline land features strong season and salt-alkali synergy. Based on this study, in different types of salinized cotton fields, soil water content peaked in April through June (arid and rainless spring and summer), decreased significantly in July through August (rainy summer and autumn), and increased somewhat in September through October (post-rainy autumn). Soil water contents in the severely salinized cotton field significantly were higher than those in other types of cotton fields; in September through October, soil water contents in moderately salinized cotton field decreased markedly, and water contents of the soil at $0-140 \mathrm{~cm}$ depths in the slightly salinized cotton field were markedly higher than those in the moderately salinized cotton field. As indicated in previous study, soil salinity accumulation will enable permeation stress to plants and preclude water content-related permeation regulating material in the plant from exerting its role, so that the moisture fails to be effectively transported to leaves (Singh et al. 2015). This study shows that, in the slightly salinized cotton field, the cotton at seedling stage was subjected to minimum salt-alkali stress, and in rainy season, the salt-alkali stress was relieved, soil water content was modest, and photosynthetic production was more robust; furthermore, in the post-rainy autumn, milder salt-alkali stress and higher soil water content were noted, leaves remained at a longer physiological stage, and photosynthetic rate was kept at a higher level for a long time. In the case of the moderately salinized cotton field, as early growth was evidently inhibited, soil water content was relatively high and vegetative growth was particularly pronounced in July through August (rainy summer and autumn), resulting in significant increases in number of flowers and number of bolls; in September through October (post-rainy autumn), soil water content dropped quickly and extent of salt-alkali stress increased markedly, thus salt-alkali drought led to evident reduction in photosynthetic rate. In the case of the severely salinized cotton field, although soil water content was high throughout reproductive stage, salt stress will undermine the water absorption capacity of plant root system by reducing soil water potential, and will further weaken the effectiveness of water conduction via the xylem so that each leaf stoma will be partially closed to reduce transpiration and chloroplast structure will be disrupted, leading to intense inhibition of photosynthesis (Rahnama et al. 2010).

\subsection{Effects of variations in photosynthetic characteristics of cotton in coastal saline cotton field on photosynthetic production and yield of cotton}


Under abiotic stresses, a plant maintains growth by altering morphological characteristics (Huang et al. 2012). The effect of salt-alkali stress on cotton in coastal saline land is also represented in photosynthate accumulation characteristic (Wang et al. 2014). Immediate impact of salt-alkali stress on photosynthetic production of cotton is one of the main causes of variation in yield level of cotton in salinized land (Dong et al. 2012). This study shows that, in coastal cotton fields varying in degree of salinization, cotton growth was maintained and cotton yield was formed, thanks to different photosynthate accumulation characteristics of the source and sink organs. In the severely salinized cotton field, photosynthate accumulation of the source and sink organs had a linear growth stage starting and ending earlier, shorter duration, shorter active mass accumulation stage, and smaller maximum growth rate; heavier salt-alkali stress and longer duration lead to low match between photosynthetic production and photothermal resource, lower photosynthetic accumulation rate (Stefanov et al. 2018), and shorter duration of fast accumulation. Therefore, photosynthate accumulation decreased significantly probably because soil salt concentration reaching a threshold caused permeation stress to the crop and disturbed nutrient ion balance, resulting in dynamic imbalance of ions in the plant, metabolic disorder of intracellular reactive oxygen, reduced photosynthesis and retarded in vivo energy metabolism, inhibited crop growth and development, and even massive cotton shriveling and yield reduction (Chen and Murata 2011); fewer harvested plants and bolls as well as lower boll weight resulted in low yield of cotton in the severely salinized cotton field. Cotton in the moderately salinized cotton field was subjected to milder salt-alkali stress, which became relieved for a while but exacerbated again at the late reproductive stage, thus, photosynthetic production matched with photothermal resource to some extent, but late salt-alkali stress enabled premature ending of photosynthate accumulation, which is very detrimental to reproductive organ growth and development, and resulted in insufficient boll development and yield reduction. Compared with those in the moderately salinized cotton field, the linear growth stage starting time, linear growth stage ending time, and maximum growth rate onset time of source-organ photosynthate accumulation in the slightly salinized cotton field were $-4 d,(-1)-3 d$, and (-1) $-(-3) d$ earlier, respectively, the linear growth stage, maximum growth rate, and active mass accumulation stage of photosynthate accumulation were $6.0 \%-16.9 \%, 8.0 \%-18.1 \%$, and $5.9 \%-17.0 \%$ higher, respectively, the linear growth stage starting time, linear growth stage ending time, and maximum growth rate onset time of sink-organ photosynthate accumulation were 14-18 d, 25-35 d, and 20-26 d earlier, respectively, and the linear growth stage, maximum growth rate, and active mass accumulation stage of photosynthate accumulation were $28.7 \%-43.0 \%, 49.7 \%-$ $50.6 \%$, and $28.7 \%-43.0 \%$ higher, respectively. Therefore, in the slightly salinized cotton field, photosynthate accumulation matched with photothermal resource well, the linear growth stage, maximum growth rate, and active mass accumulation stage were markedly higher, vigorous growth stage of the source organ started later while vigorous growth stage of the sink organ started earlier, in case over-allocation of photosynthate and vegetative growth would result in yield reduction at the vigorous growth stage; moreover, yield formation time was significantly extended, boll development was more sufficient, and individual boll weight and lint percentage were higher, facilitating allocation of more accumulated photosynthates to reproductive growth so as to improve yield effectively.

Increasing photosynthetic capacity of a crop is an effective condition of yield improvement (Feng et al. 2014; Yao et al. 2016). Therefore, routine cultivation management measures should be specifically adjusted. For severely salinized cotton fields, salt inhibition and other related agronomical measures should be strengthened to minimize the impact of salt-alkali stress on normal growth and development of cotton; for moderately salinized cotton fields, water and fertilizer management of cotton at early reproductive stage should be tightened to promote vegetative growth of cotton in case source-sink development mismatch problem arises at boll setting stage; in contrast, photosynthetic performance and photosynthetic production of cotton in the slightly salinized cotton field are less affected, where high quality efficient production of cotton can be achieved.

\section{Conclusions}

In the slightly salinized cotton field, soil water content in rainy season was lower than that at boll opening stage; the cotton was subjected to smaller salt-alkali and waterlogging stresses, and with higher photosynthetic performance and better

Page $10 / 18$ 
match between photosynthetic production and hydrothermal resource, the cotton remained at active mass accumulation stage for a long time; in the moderately salinized cotton field, evident salt-alkali stress was present at early and later reproductive stages, and yield formation stage was poorly matched with rich photothermal resource stage; in the severely salinized cotton field, the cotton was subjected to prolonged high salt-alkali stress and its photosynthetic performance became heavily suppressed, resulting in inferior photosynthetic production capacity and yield level.

\section{Declarations}

\section{Ethics approval and consent to participate}

Not applicable.

\section{Consent for publication}

Not applicable.

\section{Availability of data and materials}

The datasets used and analysed during the current study are available from the corresponding author on reasonable request.

\section{Competing interests}

The authors declare that they have no competing interests.

\section{Funding}

This research was funded by the Natural Science Foundation of Hebei Province (No. C2015301051) and Modern Agricultural Science \& Technology Innovation Project of Hebei Academy of Agriculture and Forestry Sciences (No. 2019-2-71).

\section{Author Contributions}

Conceptualization, Guoyi Feng and Yongzeng Lin; methodology, Guoyi Feng, Chitao Sun and Qian Zhang; software, Hong Qi; validation, formal analysis, Guoyi Feng, Ming Dong and Yan Wang;investigation, Xiaopeng Lei, Qinglong Liang and Shulin Wang; data curation, Guoyi Feng and Yan Wang; writing-original draft preparation, Guoyi Feng; writing-review and editing, Guoyi Feng and Yongzeng Lin; visualization, Guoyi Feng; supervision, Yongzeng Lin; project administration, Hong Qi; funding acquisition, Guoyi Feng. All authors have read and agreed to the published version of the manuscript.

\section{Acknowledgments}

We would like to thank three colleagues at Institute of Cotton, Hebei Academy of Agriculture and Forestry Sciences, including Mr. Weiming Li (researcher) for his help on operating and maintaining experiment instrument, and Miss Haiying Du (researcher) and Miss Xu Liu (assistant researcher) for their help in reviewing this article for publication.

\section{References}

1. Qadir M, Tubeileh A, Akhtar J, et al. Productivity enhancement of salt-affected environments through crop diversification. Land Degrad. Develop. 2008, 19(4): 429-453.

2. Setia R, Gottschalk P, Smith P, et al. Soil salinity decreases global soil organic carbon stocks. Sci Total Environ, 2012 , 465(6), 267-272. https://doi.org/10.1016/j.scitotenv.2012.08.028. 
3. Yang JS. Development and prospect of the research on salt-affected soils in China. Acta Pedol Sin, 2008, 45(5): 837845. (In Chinese with English abstract). https://doi.org/10.3321/j.issn:0564-3929.2008.05.010.

4. Dong H Z. Cotton farming in saline soil. Beijing: Science Press, 2010. (In Chinese).

5. Zhang SJ, Chao Y, Zhang CL, et al. Earthworms enhanced winter oilseed rape (brassica napus I.) growth and nitrogen uptake. Agr Ecosyst \& Environ, 2010, 139(4), 463-468. https://doi.org/10.1016/j.agee.2010.08.007.

6. Fall A. Sustainable management of coastal saline soils in the Saloum river Basin, Senegal. International J Biol \& Chemical Sci, 2017, 11(4):1903-1919. https://doi.org/10.4314/ijbcs.v11i4.39.

7. Shan QH, Zhang JF, Ruan WJ, et al. Response of soil quality indicators to comprehensive amelioration measures in coastal salt-affected land. Acta Ecol Sin, 2011, 31(20): 6072-6079. (In Chinese with English abstract). https://doi.org/cnki:sun:stxb.0.2011-20-025.

8. Zhang JL, Zhang Q, Wang ZY, et al. Effect of subsurface drain spacing on elution desalination for coastal saline soil. Trans Chin Soc Agric Eng, 2012, 28(9): 85-89. (In Chinese with English abstract). https://doi.org/10.3969/j.issn.10026819.2012.09.014.

9. Wang LL, Li SY, Sun XY; et al. Application of salt-isolation materials to a coastal region: Effects on soil water and salt movement and photosynthetic characteristics of Robinia pseudoacacia. Acta Ecol Sin, 2015, 35(5):1388-1398. (In Chinese with English abstract). https://doi.org/10.5846/stxb201403090402.

10. Wang RT, Sun JK, Lu ZH. Effect of soil ameliorants on the biochemical properties of coastal saline-alkali soil in the Yellow River Delta. Acta Ecol Sin, 2017, 37(2): 425-431. (In Chinese with English abstract). https://doi.org/10.5846/stxb201508031633.

11. Kao WY, Tasi T, Tasi HC, et al. Response of three Glyeine species to salt stress. Environ Exp Bot, 2006, 56: 120-125. https://doi.org/10.1016/j.envexpbot.2005.01.009.

12. Yu, S. X. Present situation and development trend of cotton production in China. Engineering Sci, 2013, 15(4): 9-13. (In Chinese with English abstract). https://doi.org/cnki:sun:gckx.0.2013-04-003.

13. Dong HZ,Xin CS, Li WJ, et al. Characteristics of salinity and fertility in coastal saline cotton fields in Shandong and their effects on cotton emergence. Cotton Sci, 2009, 21(4): 290-295. (In Chinese with English abstract). https://doi.org/10.3969/j.issn.1002-7807.2009.04.007.

14. Farquhar GD, Sharkey TD. Stomatal conductance and photosynthesis. Annual Rev Plant Physiol, 2011, 33: $317-345$. https://doi.org/10.1146/annurev.pp.33.060182.001533.

15. Paz RC, Reinoso H, Espasabdin FD, et al. Akaline, saline and mixed saline-alkaline stresses induce physiological and morpho-anatomical changes in Lotus tenuis shoots. Plant Biol, 2014, 16(6): 1042-1049. https://doi.org/10.1111/plb.12156.

16. Kalaji HM, Jajoo A, Oukarroum A, et al. Chlorophyll a fluorescence as a tool to monitor physiological status of plants under abiotic stress conditions. Acta Physiol Plant, 2016, 38: 102.https://doi.org/10.1007/s11738-016-2113-y.

17. Yang JY, Zheng W, Tian Y, et al. Effects of various mixed salt-alkaline stresses on growth, photosynthesis, and photosynthetic pigment concentrations of Medicago ruthenica seedlings. Photosynthetica, 2011, 49(2): $275-284$. https://doi.org/10.1007/s11099-011-0037-8.

18. Kalaji HM, Rac ková L, Paganová V, et al. Can chlorophyll-a fluorescence parameters be used as bio-indicators to distinguish between drought and salinity stress in Tilia cordata Mill? Environ Exp Bot, 2017, 152: 149-157. https://doi.org/10.1016/j.envexpbot.2017.11.001.

19. Zushi K, Matsuzoe N. Using of chlorophyll a fluorescence OJIP transients for sensing salt stress in the leaves and fruits of tomato. Sci Hortic-amsterdam, 2017, 219: 216-221. https://doi.org/10.1016/j.scienta.2017.03.016.

20. Grieve CM, Lesch SM, Mass EV, et al. Leaf and spikelet primordia initiation in salt-stressed wheat. Crop Sci, 1992, 33(6): 1286-1294. https://doi.org/10.2135/cropsci1993.0011183X003300060034x.

Page $12 / 18$ 
21. Sun YL, Hong SK. Effects of citric acid as an important component of the responses to saline and alkaline stress in the halophyte Leymus chinensis (Trin. ). Plant Growth Regul, 2011, 64: 129-139. https://doi.org/10.1007/s10725-0109547-9.

22. Dong HZ, ,Li WJ, Eneji A E, et al. Nitrogen rate and plant density effects on yield and late-season leaf senescence of cotton raised on a saline field. Field Crop Res, 2012, 126(1): 137-144. https://doi.org/10.1016/j.fcr.2011.10.005.

23. Singh M, Kumar J, Singh S, et al. Roles of osmoprotectants in improving salinity and drought tolerance in plants: a review. Rev Environ Sci Biotechnol, 2015, 14: 407-426. https://doi.org/10.1007/s11157-015-9372-8.

24. Rahnama A, James RA, Poustini K, et al. Stomatal conductance as a screen for osmotic stress tolerance in durum wheat growing in saline soil. Funct Plant Biol, 2010, 37: 255-263. https://doi.org/10.1071/FP09148.

25. Huang ZR, Long XH, Wang L, et al. Growth, photosynthesis and H +-ATPase activity in two Jerusalem artichoke varieties under $\mathrm{NaCl}$-induced stress. Process Biochem, 2012, 47(4): 591-596.

https://doi.org/10.1016/j.procbio.2011.12.016.

26. Wang LL, Sun XY, Li SY, et al. Application of organic amendments to a coastal saline soil in North China: Effects on soil physical and chemical properties and tree growth. PLoS One, 2014, 9(2): e89185.

https://doi.org/10.1371/journal.pone.0089185.

27. Stefanov M, Yotsova E,Markovska Y, et al. Effect of high light intensity on the photosynthetic apparatus of two hybrid lines of Paulownia grown on soils with different salinity. Photosynthetica, 2018, 56(3):832-840.

https://doi.org/10.1007/s11099-017-0735-y.

28. Chen TH, Murata N. Glycinebetaine protects plants against abiotic stress: mechanisms and biotechnological applications. Plant Cell Environ, 2011, 34: 1-20. https://doi.org/10.1111/j.1365-3040.2010.02232.x.

29. Feng GY, Gan XX, Yao YD, et al. Comparisons of photosynthetic characteristics in relation to lint yield among F1 hybrids, their F2 descendants and parental lines of cotton. J Integr Agr, 2014, 13(9): 1909-1920.

https://doi.org/10.1016/S2095-3119(13)60690-5.

30. Yao HS, Zhang YL, Yi XP, et al. Cotton responds to different plant population densities by adjusting specific leaf area to optimize canopy photosynthetic use efficiency of light and nitrogen. Field Crop Res, 2016, 188: 10-16.

https://doi.org/10.1016/j.fcr.2016.01.012

\section{Figures}




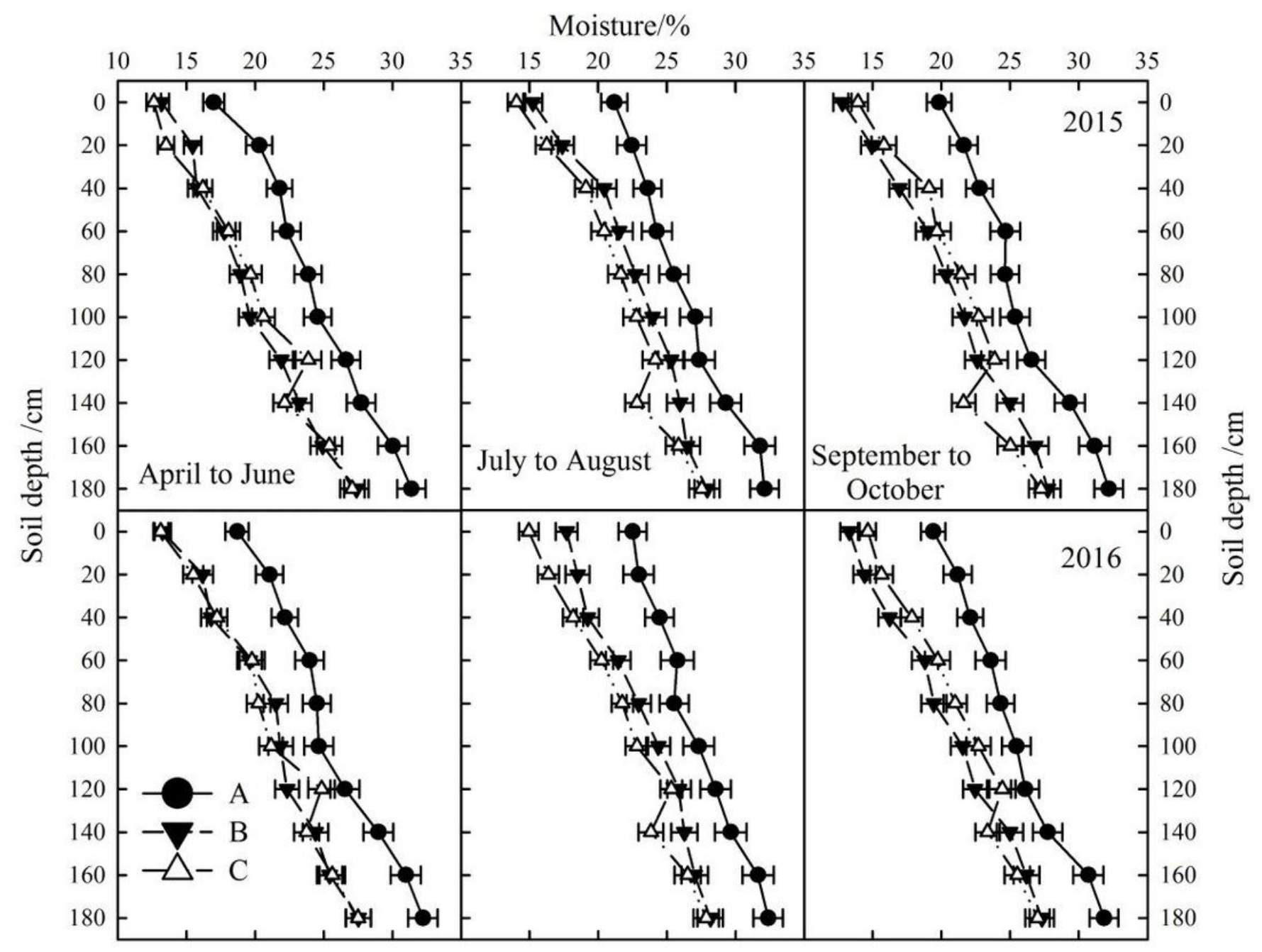

Figure 1

Vertical distribution and variation of soil moisture in the cotton field during the cotton growth period relative to soil salinealkali level Note: A: Cotton field with heavy saline-alkali degree; B: Cotton field with middle saline-alkali degree; C: Cotton field with mild saline-alkali degree. 


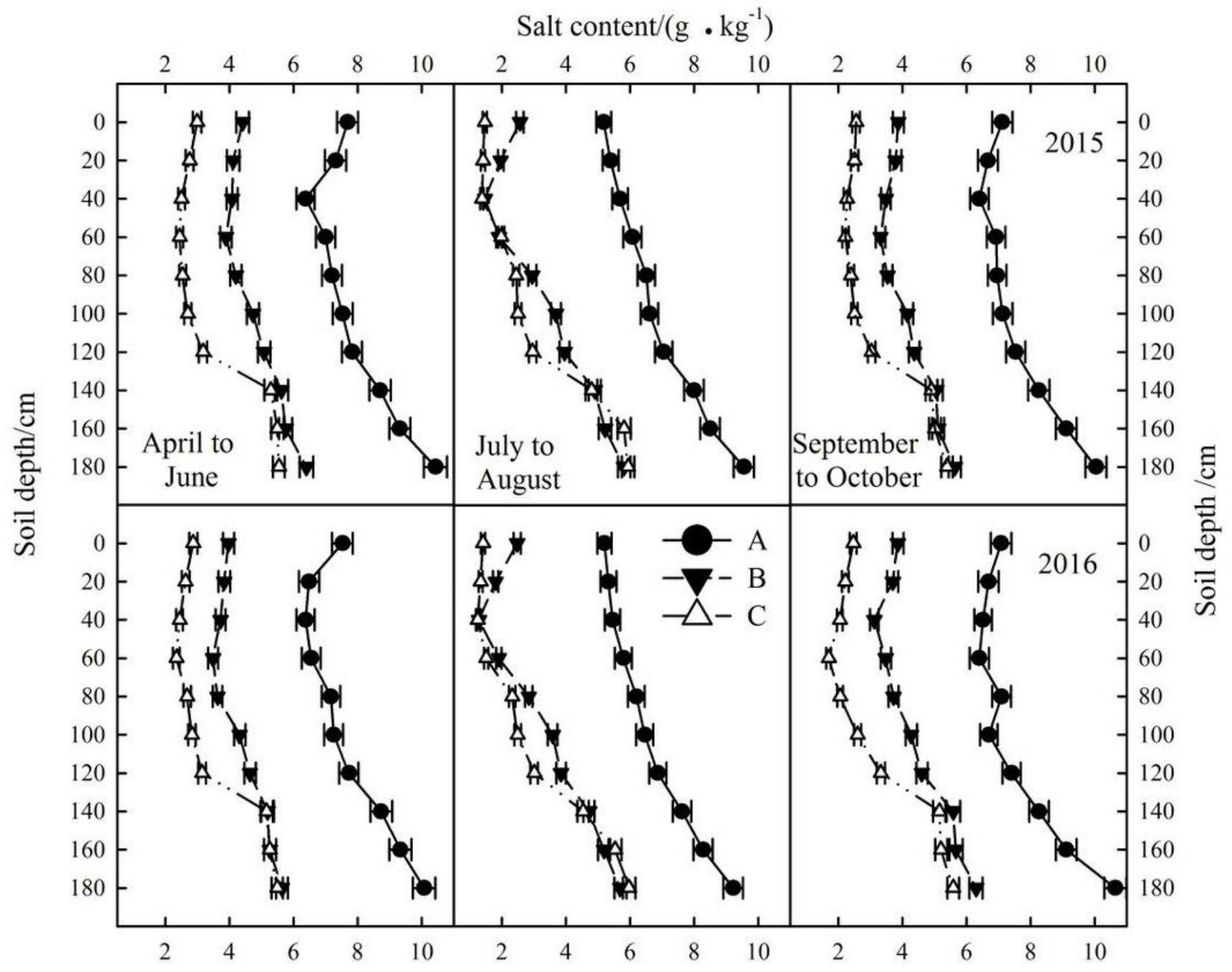

Figure 2

Vertical distribution and variation of soil salt content in the cotton field during the cotton growth period relative to soil saline-alkali level Note: A: Cotton field with heavy saline-alkali degree; B: Cotton field with middle saline-alkali degree; C: Cotton field with mild saline-alkali degree. 


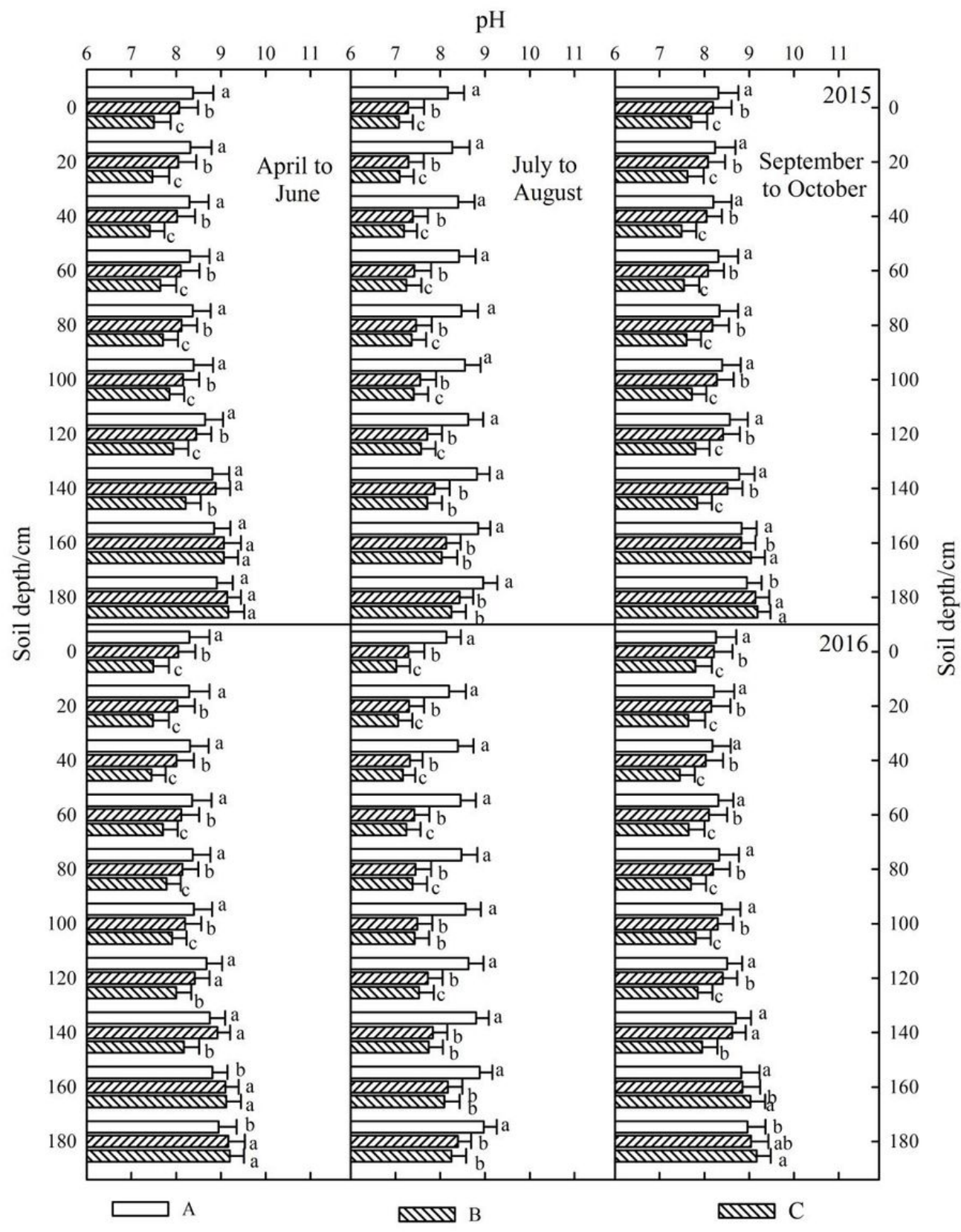

\section{Figure 3}

Vertical distribution and variation of soil $\mathrm{pH}$ in the cotton field during the cotton growth period relative to soil saline-alkali level. Note: A: Cotton field with heavy saline-alkali degree; B: Cotton field with middle saline-alkali degree; C: Cotton field with mild saline-alkali degree. Different letters in the same column of soil depth mean significant difference at the 0.05 probability level 


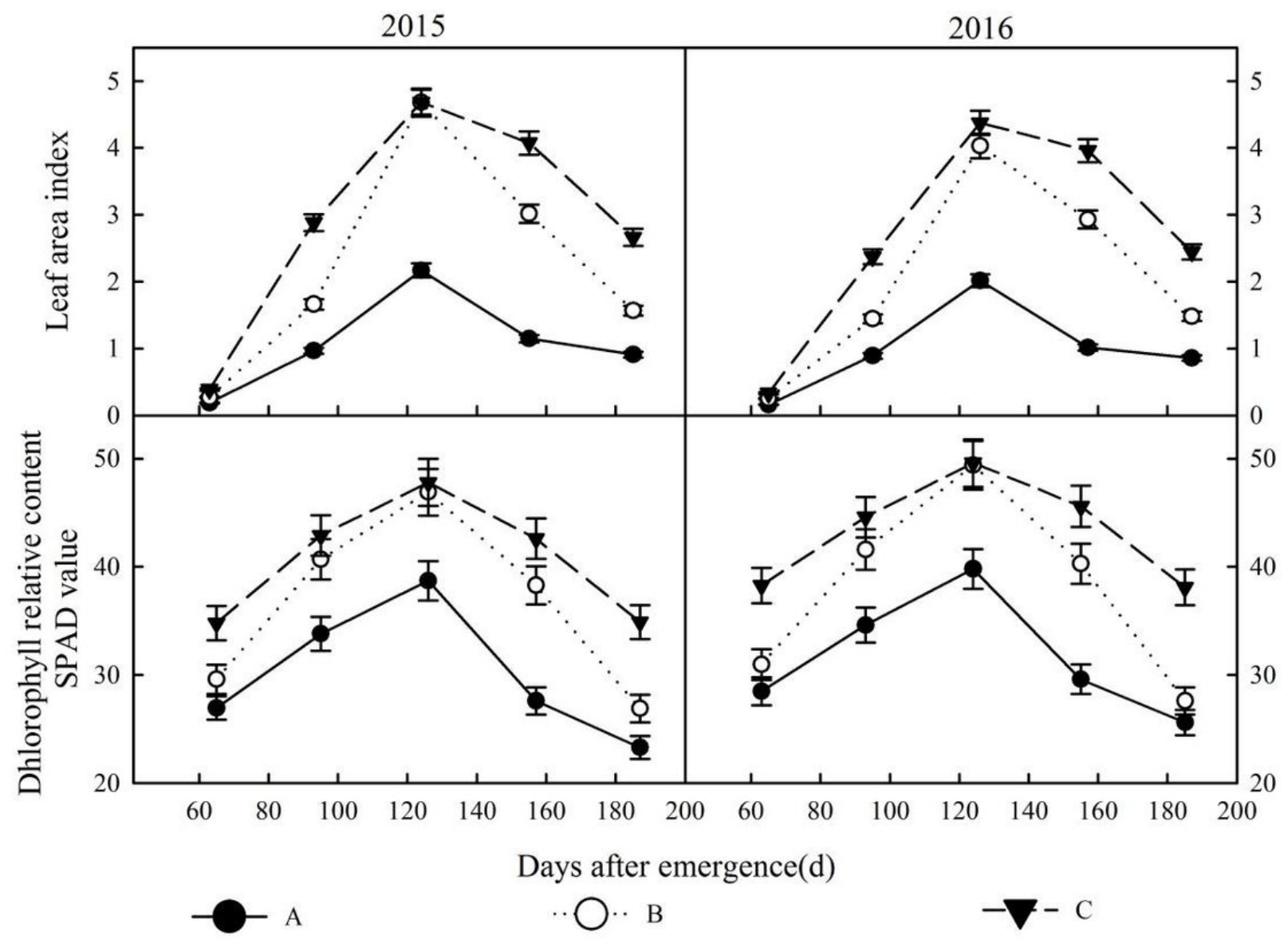

Figure 4

Change of leaf area and SPAD value in the cotton field during the growth period relative to soil saline-alkali level Note:A: Cotton field with heavy saline-alkali degree; B: Cotton field with middle saline-alkali degree; C: Cotton field with mild salinealkali degree. 


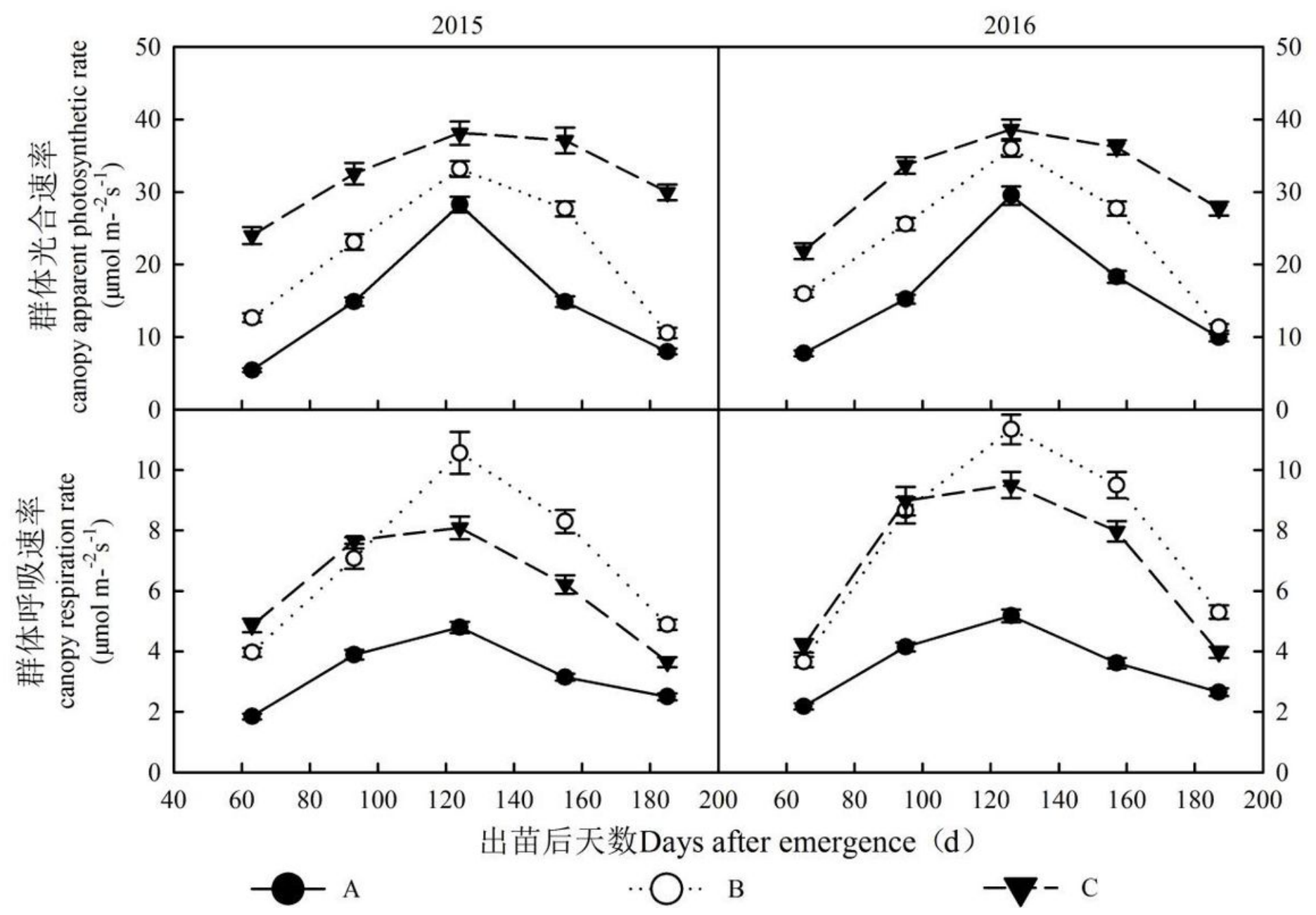

Figure 5

Change of canopy apparent photosynthetic rate and respiration rate in the cotton field during the growth period relative to soil saline-alkali level Note:A: Cotton field with heavy saline-alkali degree; B: Cotton field with middle saline-alkali degree; C: Cotton field with mild saline-alkali degree. 